\title{
Estudo de desempenho à fadiga de base cimentada tipo BGTC na BR-101/SE
}

\author{
Rodrigo da Silva Nascimento ${ }^{1}$, Fernando Silva Albuquerque ${ }^{2}$ \\ 1Departamento Nacional de Insfraestrutura de Transporte - DNIT/SE, rodrigo.nascimento@dnit.gov.br \\ 2Departamento de Engenharia Civil, Universidade Federal de Sergipe, albuquerque.f.s@ufs.br
}

\section{Recebido:}

18 de abril de 2017

\section{Aceito para publicação:}

10 de outubro de 2017

Publicado:

30 de abril de 2018

Editor de área:

Jorge Barbosa Soares

\section{Palavras-chaves:}

Brita graduada tratada com cimento,

Fadiga,

Fator laboratório-campo.

\section{Keywords:}

Cemented crushed stone, Accumulated damage,

Shift factor.

DOI:10.14295/transportes.v26i1.1358

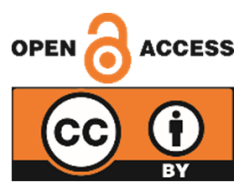

\begin{abstract}
RESUMO
O ganho de rigidez ao pavimento fez com que o uso de camada de brita graduada tratada com cimento (BGTC) passasse a ser frequente em projetos de pavimentos novos no Brasil. Seu uso em vias de grande frequência de carregamento se apresenta como uma solução viável, podendo ser empregada tanto em base, quanto em sub-base. Possivelmente, a grande desvantagem do uso da BGTC esteja relacionada ao seu processo de ruptura quase-frágil por fadiga, o que leva algumas vezes ao dano acelerado à estrutura do pavimento. Nesta pesquisa, foi feita a determinação da vida de fadiga em laboratório e definido um fator laboratório-campo, extraído do acompanhamento do desempenho estrutural de trecho monitorado na BR-101/SE, pela aplicação do princípio do dano acumulado da Hipótese de Miner. Também foi acompanhada e determinada a evolução do dano causado pela ação do tráfego, bem como a sua influência na redução da rigidez deste material ao longo do tempo, por um período de trinta e seis meses, o que permitiu ajustar um modelo que relaciona a rigidez da camada ao dano acumulado.
\end{abstract}

\section{ABSTRACT}

The increase of stiffness to the pavement afford usual application of the cemented crushed stone (CCS) for the new pavements designs in Brazil. The increase of overall pavement stiffness reveals an advantage for high volume roads, can applied as a base or subbase, that is, in semi-rigid and inverted semi-rigid pavements, respectively. Perhaps, the major disadvantage of the CCS is its weak fatigue cracking process, which often causes accelerated damage to the pavement structure. On the present research, the fatigue life was determined in laboratory and calibrated with a laboratory-field factor extracted from the monitoring of the structural performance of the monitored section in BR-101/SE, by applying the cumulative damage principle of Hypothesis of Miner. It was also monitored and determined the evolution of the damage caused by the traffic action, as well as its influence in reducing the rigidity of this material over time, for a period of thirty-six months, which allowed calibrating a model that relates the rigidity of the layer to the accumulated damage.

\section{INTRODUÇÃO}

A crescente utilização de bases cimentadas do tipo BGTC em rodovias de tráfego intenso e pesado traz um grande desafio aos projetistas, uma vez que o atual método de dimensionamento de pavimentos adotado no Brasil não trata especificamente deste tipo de material, tão pouco dos reais mecanismos que governam os danos às estruturas dos pavimentos.

Neste contexto, pretendeu-se neste trabalho avaliar o processo de degradação por fadiga da BGTC em laboratório, por meio dos ensaios de vida de fadiga, e em campo, por meio de levantamento das condições estruturais de um trecho monitorado na BR-101/SE. A avaliação conjunta foi importante para estabelecer uma relação entre as características mecânicas obtidas em laboratório com os dados obtidos por meio de retroanálise das bacias deflectométricas do trecho monitorado. 


\section{CARACTERÍSTICAS DO TRECHO MONITORADO}

O Trecho Monitorado A (TMA) é um trecho em tangente com boa visibilidade, constituído de sub-base de solo (A-2-4 na classificação HRB), com base de BGTC, com 3\% de cimento Portland tipo CP-II-F32, uma camada asfáltica intermediária de Concreto Asfáltico Usinado a Quente (CAUQ) na faixa B de granulometria do DNIT e uma camada de CAUQ com polímero elastomérico do tipo SBS (Styrene - butadiene - styrene) na faixa C do DNIT. 0 subleito é constituído de solo areno argiloso (A-2-6 na classificação HRB), com $19 \%$ de argila e $20 \%$ de índice de plasticidade. Na Figura 1a podem-se observar as características mecânicas iniciais de cada uma das camadas e subleito do TMA, bem como a evolução dos módulos de resiliência ao longo do período de monitoramento (conforme descrito nos itens 3.1 e 4.4.1).

\section{MATERIAIS E MÉTODOS}

Foi reproduzida nesta pesquisa a mesma dosagem utilizada no TMA para a BGTC, a qual foi definida pela equipe projetista da obra. A BGTC com $3 \%$ de cimento em relação à massa seca da mistura foi compactada no Proctor modificado, obtendo-se valor de umidade ótima de 8,5\% e densidade máxima de 22,07 $\mathrm{kN} / \mathrm{m}^{3}$. A brita utilizada na BGTC tem origem granítica, com índice de forma de 1,5, valor de equivalente de areia de $65 \%$ e perda por abrasão Los Angeles de $25 \%$. Para reproduzir uma mistura com as mesmas características da BGTC utilizada na obra, foram utilizados três tipos de materiais britados, que, misturados em determinadas proporções, apresentassem a mesma granulometria da obra. As proporções dos materiais utilizados para composição da mistura foram de $30 \%$ para o pó de pedra e brita 9,5 mm e de $40 \%$ para a Brita de 19,0 mm. Além disso, 3\% de cimento em relação à massa seca dos agregados e 8,5\% de água em relação ao material passante na peneira com abertura de 4,8 $\mathrm{mm}$. A curva granulométrica utilizada atendeu a faixa II indicada na especificação de serviço ES-P-16/05 do DER-PR. A curva granulométrica obtida está representada na Figura 2.



(a)

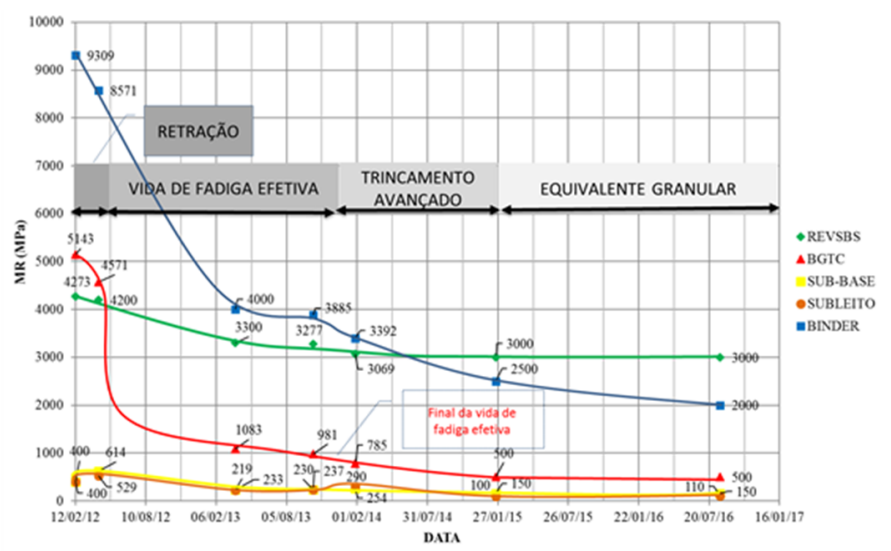

(b)

Figura 1: (a) Propriedades mecânicas iniciais das camadas do TMA; e (b) evolução de seus módulos elásticos em função do tempo (Fonte: MENDONÇA, 2014; NASCIMENTO, 2017) 


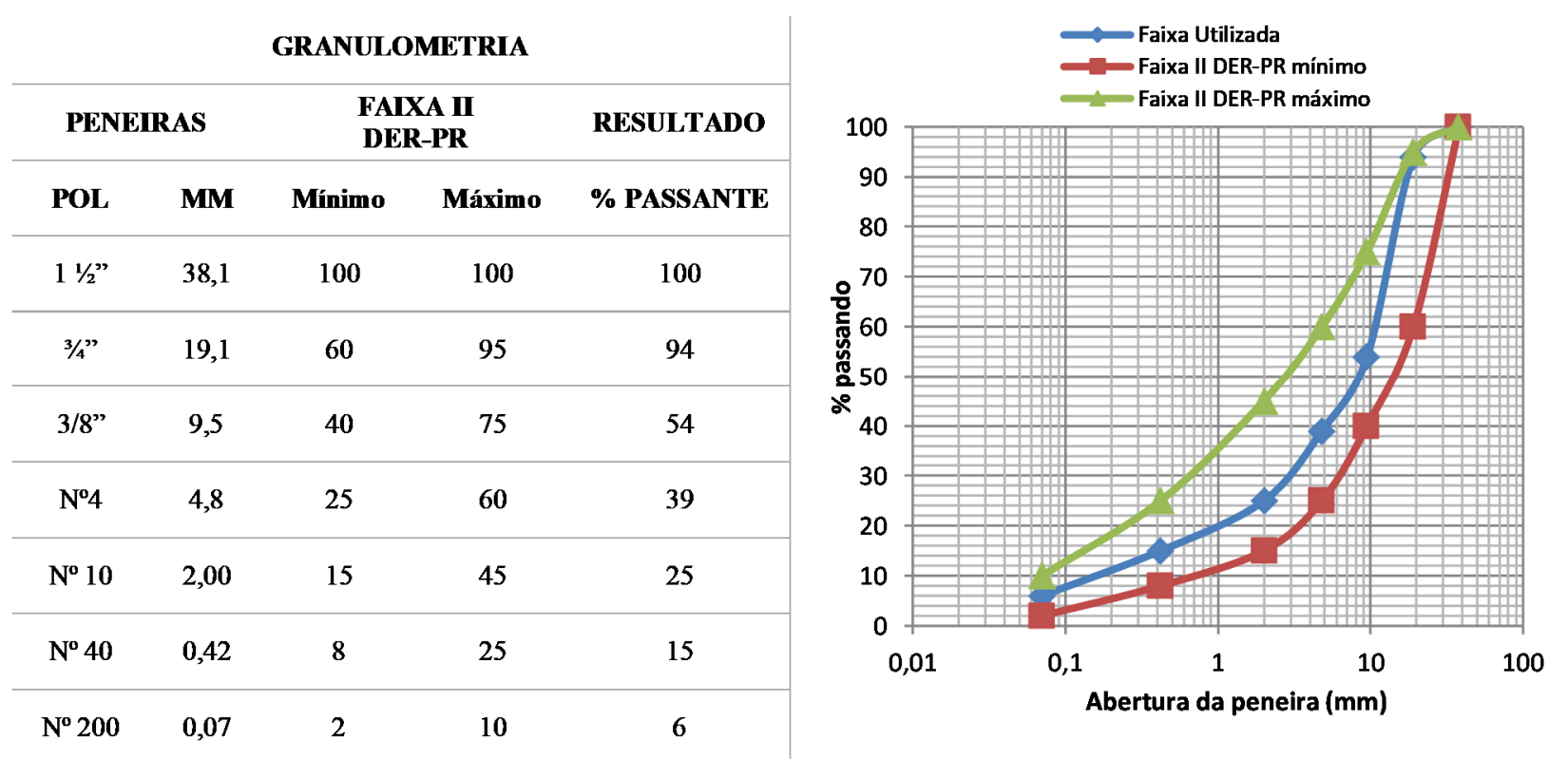

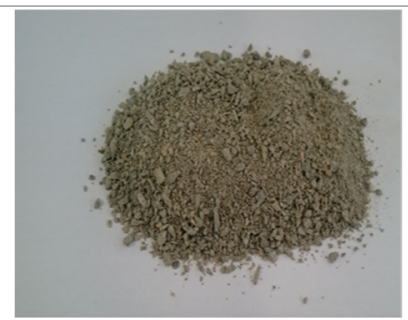

Pó de Pedra

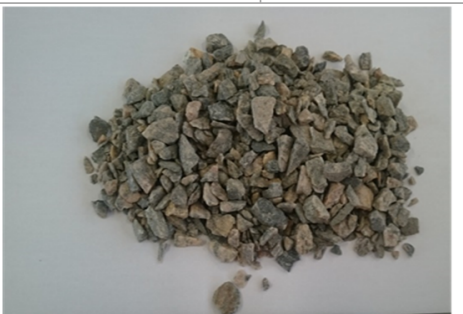

Brita 9,5 mm

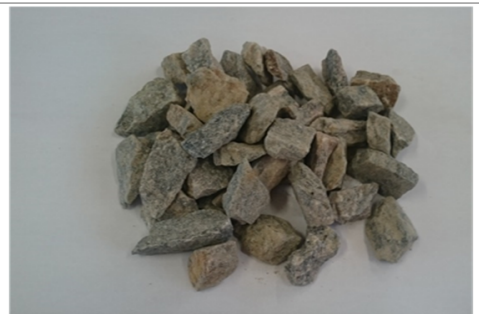

Brita $19 \mathrm{~mm}$

Figura 2: Granulometria da BGTC utilizada no trecho monitorado.

\subsection{Avaliação estrutural do pavimento}

A avaliação estrutural do pavimento estudado nesta pesquisa foi feita por processo não destrutivo. Foram levantadas bacias deflectométricas utilizando Deflectógrafo Digital (Viga Benkelman Eletrônica) e Falling Weight Deflectometer (FWD), as quais, posteriormente, passaram por processo de retroanálise para estimar os módulos de resiliência das camadas e do subleito (apresentados na Figura 1b).

Os resultados de módulos de resiliência obtidos foram agrupados de forma que fosse observado o comportamento temporal em campo, ou seja, para cada medição de deflexão feita em campo, foram calculados os módulos das camadas e, consequentemente, observado seu comportamento ao longo dos anos. Esta análise foi focada, principalmente, no processo de fadiga da BGTC, que segundo Mendonça (2014), governou as ocorrências de dano à estrutura do pavimento no TMA.

Em Mendonça (2014) também foram extraídos os resultados dos dois primeiros anos de avaliação estrutural do pavimento, os quais foram somados aos levantamentos de bacias deflectométricas realizados nesta pesquisa, compondo um histórico de cinco anos de operação do TMA.

Para obtenção das bacias deflectométricas, adotou-se o método preconizada pela norma DNIT 133/2010-ME, onde é aplicada uma carga de 8,2 tf em um eixo simples de rodas duplas traseiras de um caminhão basculante.

Para efeito comparativo, os valores das deflexões medidos, foram corrigidos de acordo com as temperaturas do revestimento durante o ensaio, através do modelo de Park e Kim (1997), para uma temperatura padronizada de $25^{\circ} \mathrm{C}$.

Onde:

$$
W_{t_{0}}=10^{-n\left(t-t_{0}\right)} \cdot W_{t}
$$

$n=5,807 \times 10^{-6}\left(h_{a c}\right)^{1,4635}$ ao longo da trilha de roda; ou

$n=6,560 \times 10^{-6}\left(h_{a c}\right)^{1,4241}$ ao longo do centro da faixa de rolamento; 
$h_{a c}=$ espessura da camada de concreto asfáltico (mm);

$W_{t 0}=$ deflexão corrigida $\left(\mathrm{x} 10^{-2} \mathrm{~mm}\right)$ para a temperatura $\mathrm{t}_{0}\left({ }^{\circ} \mathrm{C}\right)$ de referência;

$W_{t}=$ deflexão medida $\left(\mathrm{x} 10^{-2} \mathrm{~mm}\right)$ na temperatura $\mathrm{t}_{\mathrm{t}}\left({ }^{\circ} \mathrm{C}\right)$ do ensaio.

Os levantamentos deflectométricos foram feitos a cada estaca do TMA, alternando-se entre a trilha de roda interna e externa, sempre na faixa direita de rolamento. Com os dados obtidos nos levantamentos deflectométricos, aliados às características geométricas da seção transversal e os tipos de materiais empregados, permitiu-se a realização do processo de retroanálise para determinação dos módulos de resiliência de cada camada do pavimento.

Nesta pesquisa foi utilizado o programa Análise Elástica de Múltiplas Camadas (AEMC), que é um módulo do sistema SISPAV (FRANCO, 2007), para retroanálise das bacias deflectométricas corrigidas.

A iteração do processo de retroanálise foi feita de forma manual, já que o AEMC é um software de análise de pavimentos, até que o resultado da raiz do erro médio quadrático normalizado (RMSE) entre deflexões da bacia teórica e de campo fosse menor que $5 \%$.

\subsection{Ensaios de laboratório}

\subsubsection{Resistência à compressão simples}

Foram realizados ensaios de compressão axial para a determinação da resistência a compressão simples da BGTC para um tempo de cura de 7, 14 e 28 dias, com pelo menos dois corpos de prova para cada idade. Os corpos de prova tinham formato cilíndrico com dimensões de $100 \mathrm{~mm}$ de diâmetro por 200 mm de altura, e foram moldados em condições de umidade ótima e densidade máxima por compactação por impacto, sendo para isto empregada a energia de compactação do Proctor modificado em cinco camadas.

A desmoldagem do corpo de prova foi feita de forma imediata, seguido do encaminhamento para cura em câmara úmida com temperatura e umidade relativa do ar controladas em $30 \pm 2^{\circ} \mathrm{C}$ e $85 \%$, respectivamente, sem imersão em água, até a data de rompimento.

A carga de ensaio foi aplicada continuamente, com velocidade de carregamento de $(0,45 \pm 0,15)$ $\mathrm{MPa} / \mathrm{s}$, sendo constante durante todo o ensaio, até uma queda brusca da força que indicava sua ruptura (Figura 3a). 0 ensaio foi realizado em conformidade com a ABNT NBR 5739:2007 e ASTM C39/C39M16. Os ensaios foram realizados na Máquina Universal de ensaios, modelo EMIC-DL - 2000, fabricada pela EMIC e instalada Laboratório de Materiais de Construção e Estruturas - LAMCE do Departamento de Engenharia Civil - DEC da UFS. Os dados foram captados por meio do programa TESC que acompanha o equipamento.

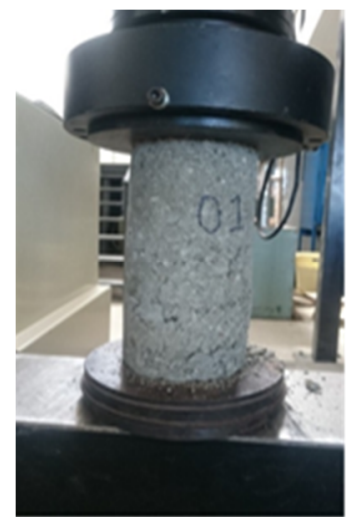

(a)

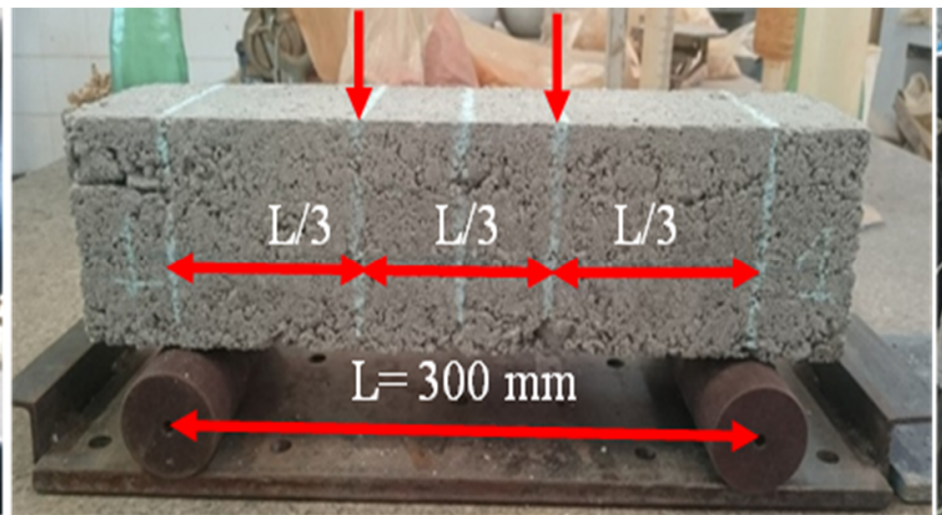

(b)

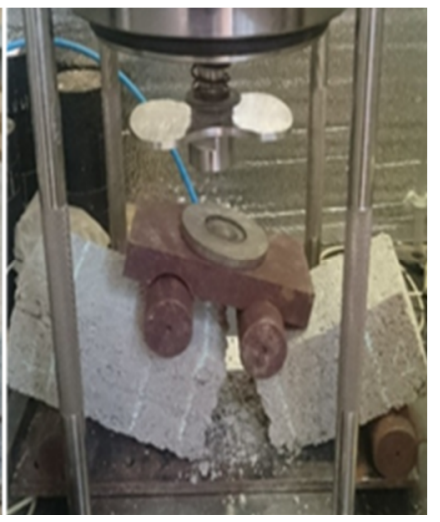

(c)

Figura 3: (a) Detalhe do ensaio de compressão simples; (b) Esquema do ensaio de tração na flexão de quatro pontos; e (c) corpo de prova após ruptura por fadiga 


\subsubsection{Resistência à tração}

Foi determinada a resistência à tração na flexão da BGTC em corpos de prova prismáticos, na forma de vigotas, com dimensões de $100 \mathrm{~mm}$ x $100 \mathrm{~mm}$ x $400 \mathrm{~mm}$, definida em função do diâmetro máximo nominal das misturas $\left(D_{\max }=19 \mathrm{~mm}\right)$ e obedecendo a relação de que a altura do corpo de prova deve ser de 1/3 (um terço) da distância entre os apoios (L), seguindo o critério da norma AS1012 (STANDARDS AUSTRALIA, 2000) e da ASTM C78/C78M-15b (ASTM, 2015).

Os corpos de prova foram moldados em compactação por prensagem e em três camadas de igual espessura, com controle de massa e altura de cada camada (Figura 4a). Durante a moldagem foram retiradas amostras de material para verificação da umidade de moldagem. 0 grau de compactação era avaliado pela massa de material contido no molde, ou seja, subtraindo a massa do conjunto material e molde pela massa do molde. Cada uma das três camadas era submetida a uma força de compressão, de tal forma que a massa específica determinada no ensaio de compactação, para a energia do Proctor modificada, fosse atingida ao final da moldagem. Após a compactação de cada camada, sua superfície era escarificada para permitir um melhor entrosamento entre as camadas, diminuindo a estratificação entre elas (Figura 4b). Na última camada, o corpo de prova passava por um processo de acabamento (Figura 4c) com substituição de material mais grosso por material mais fino para preenchimento de eventuais vazios, além de rasado junto ao molde para garantir uma superfície livre de ondulações (Figura 4d) que pudessem influenciar nos resultados dos ensaios.

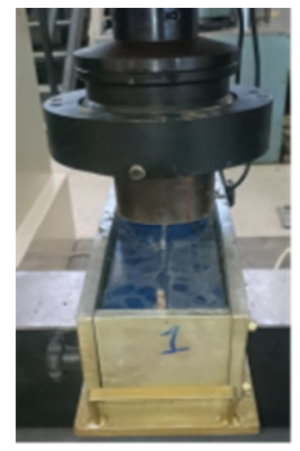

(a)



(b)

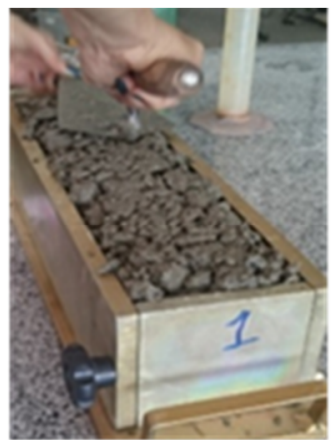

(c)

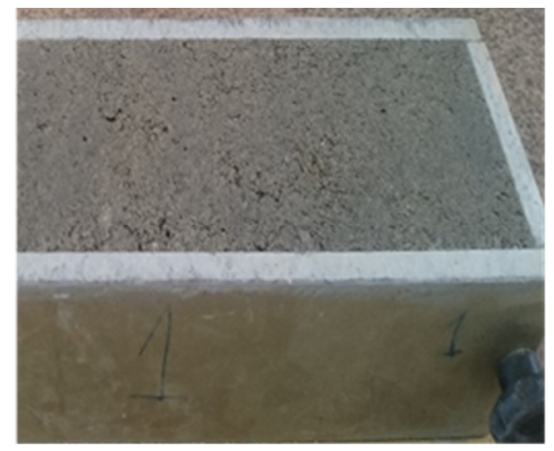

(d)

Figura 4: (a) Moldagem do CP por prensagem; (b) escarificação; (c) acabamento; e (d) superfície acabada.

Os corpos de prova eram mantidos no molde e envoltos em plástico durante as primeiras 48 horas de cura em câmara úmida, com temperatura e umidade relativa do ar controladas em $30 \pm 2^{\circ} \mathrm{C}$ e $85 \%$, respectivamente, sem imersão em água. Este processo visava garantir um ganho de resistência inicial que permitisse desmoldar sem danificar o corpo de prova, além de evitar a perda rápida de umidade para o ambiente. Após este período, era feita a desmoldagem, retornando os corpos de prova para a câmara úmida, até finalizar a cura de 28 dias.

Durante o ensaio, a carga foi aplicada uniformemente em dois pontos de uma das faces da seção transversal localizados no terço médio do vão e em outros dois pontos formados pelos apoios inferiores em sua face oposta, o que fez com que à carga aplicada promovesse uma distribuição mais uniforme dos esforços de tração e flexão ao longo da vigota (Figura $3 b$ ).

A prensagem dos corpos de prova para moldagem e os ensaios de tração, foram realizados no mesmo equipamento do ensaio de compressão simples. Durante o ensaio a carga foi aplicada continuamente e sem choque, com taxa de carregamento de $900 \mathrm{kPa} / \mathrm{min}$, conforme prevê a ASTM C78 (2015), até a ruptura da amostra.

0 valor da resistência à tração na flexão $\left(R_{T, f}\right)$ foi calculado pela equação 2$)$, a partir da carga máxima aplicada $F(\mathrm{~N})$ e da geometria da viga, sendo $L$ a distância entre os apoios, $b$ a largura e $d$ a altura do corpo de prova, todos dados em milímetros. 


$$
R_{t, f}(M P a)=\frac{F \cdot L}{b \cdot d^{2}}
$$

Para a determinação da resistência a tração na flexão $\left(R_{T, f}\right)$, foram moldados cinco corpos de prova prismáticos para a idade de 28 dias. 0 valor de $R_{T, f}$ foi utilizado como parâmetro no cálculo dos níveis de tensão a serem aplicados nos ensaios de fadiga, que também foram feitos com cura de 28 dias.

\subsubsection{Vida de fadiga da BGTC}

Para a determinação da vida de fadiga da BGTC, foi feita a aplicação de um carregamento cíclico (dinâmico) em um corpo de prova prismático, idêntico ao utilizado no ensaio de tração na flexão. Os corpos de prova passaram por um processo de cura de 28 dias em câmara úmida até a data de realização do ensaio (GNANENDRAN e PAUL, 2016).

Os ensaios foram realizados no Sistema Integrado de Ensaio para Misturas Betuminosas e Solos (SIEMBS) por meio de adaptações. A configuração do ensaio utilizada foi do tipo tensão controlada, ou seja, com aplicação de carga cíclica de magnitude constante e deformações resultantes variando pouco durante o ensaio, com pico na ruptura. Com base no procedimento utilizado pela AUSTROADS (2008), o ciclo de atuação das cargas foi de $1 \mathrm{~Hz}$ (o procedimento descrito sugere ciclo de $1 \mathrm{ou} 2 \mathrm{~Hz}$ ), com $250 \mathrm{~ms}$ de aplicação do pulso e 750 ms de intervalo de alívio entre uma aplicação e outra. Segundo Yeo (2011) ensaios com frequências maiores tendem a superestimar a vida de fadiga dos materiais cimentados.

Baseado no procedimento utilizado pela AUSTROADS (2008), que indica uma faixa de aplicação de tensão entre $60 \%$ e $90 \%$ da tensão de ruptura, foram escolhidos três níveis de tensão: 90\%, 85\%, e 75\% do valor da tensão de ruptura por tração na flexão obtida no respectivo ensaio. As opções de ciclo de atuação e os patamares de tensão tiveram como base o procedimento utilizado e descrito por YEO (2008), e visou proporcionar uma condição de carregamento mais severa (JITSANGIAM et al., 2016).

Um dos critérios para determinação da vida de fadiga de bases cimentadas está baseado na redução do módulo elástico ao longo dos ciclos de carregamento. Em laboratório, pode-se considerar que o material rompe por fadiga quando este atinge um valor de módulo equivalente a $50 \%$ do valor inicial, ou um número de ciclos de 1 milhão, ou, ainda, com a ruptura clássica da amostra (YEO, 2008). Nesta pesquisa, o critério de determinação do número $N$, que representa a quantidade de ciclos necessários para a fadiga do material em cada nível de tensão do ensaio, foi o número de ciclos que o corpo de prova chegou à ruptura clássica (Figura 3c). Já em campo, o indicador do final da vida de fadiga efetiva ou ruptura por fadiga da base cimentada foi quando o módulo elástico retroanalisado da mesma atingiu entre 700 e 800 MPa (SAPEM, 2014; AASHTO, 2004).

\subsection{Proposta de modelo de fadiga}

O modelo de previsão de desempenho à fadiga de BGTC foi obtido a partir da linha de tendência do gráfico gerado por resultados de ensaios de vida de fadiga realizados em laboratório. 0 gráfico indicou a relação entre a variável independente, que neste estudo foi a deformação específica inicial de tração $\left(\varepsilon_{t}\right)$, e a variável dependente, que foi o número de ciclos de carregamento $\left(N_{f}\right)$ que causou a ruptura do corpo de prova. Baseado em alguns métodos de dimensionamento de pavimentos (SAPEM, 2014; AUSTROADS, 2004), é esperado um comportamento exponencial da linha de tendência, com diminuição dos valores de $N_{f}$ à medida que crescem os valores iniciais medidos de $\varepsilon_{t}$ para ensaios de tensão controlada. A escolha da deformação específica como variável independente resultou de uma prévia análise do comportamento de camadas cimentadas, que traduz melhor o acúmulo de danos por fadiga e a redução de rigidez ao longo do tempo (MENDONÇA, 2014; SAPEM, 2014; AUSTROADS, 2004). Acredita-se que modelos determinísticos baseados na deformação na fibra inferior da camada cimentada representem melhor o acúmulo linear de danos por fadiga (Hipótese de Miner). Portanto, optou-se por esta relação na modelagem de fadiga, uma vez que as deformações crescem proporcionalmente ao dano acumulado nas camadas cimentadas (YEO, 2008). 


\subsubsection{Fator laboratório-campo}

Nesta pesquisa, em conjunto com os dados determinados em laboratório, que compõem o modelo de previsão de desempenho à fadiga da BGTC, foi feita uma calibração deste modelo com os dados do levantamento estrutural do trecho monitorado. Estes dados foram utilizados para determinação do módulo elástico da camada de BGTC e sua variação ao longo do período de avaliação, visando verificar o fim da vida de fadiga efetiva ou ruptura por fadiga. 0 momento de ruptura efetiva em campo da camada de BGTC foi definido quando o seu módulo elástico atingiu valor igual ou inferior a 800 MPa (SAPEM, 2014; AASHTO, 2004).

Foram determinadas, através da teoria do sistema de camadas elásticas, as tensões e deformações iniciais, provenientes do perfil de tráfego no TMA. Tais tensões e deformações também foram calculadas para intervalos de 3 meses, com inserção do incremento de tráfego no período e seu respectivo carregamento. 0 conjunto das tensões e deformações foi responsável pelo acúmulo de danos à camada de BGTC até que acontecesse o fim da sua "vida de fadiga", neste caso, estabelecido pela perda de rigidez indicada pela diminuição no valor do módulo de resiliência retroanalisado para a camada. 0 número de repetições de cada tensão e/ou deformação no pavimento em operação foi relacionado ao correspondente valor no modelo de fadiga obtido em laboratório, tornando possível obter uma relação entre o número de ciclos de carregamento em campo e o número de ciclos fornecido pelo modelo de laboratório. Este fator de correção foi aqui chamado de fator laboratório-campo.

\subsection{Estudo de Tráfego}

Estudo de pesagem e contagem volumétrica e classificatória de tráfego, feito no ano de 2012, indicaram que cerca de $66 \%$ do tráfego era de veículos de passeio e motos, e que $34 \%$ era constituído de veículos de carga, ônibus e outros. Foi quantificada a passagem de cinco tipos de eixos de carga. 0 perfil da distribuição destes eixos no tráfego de veículos comerciais indica que o ESRS (eixo simples de roda simples) corresponde a $38,68 \%$ da quantidade de eixos de carga que solicita a via, seguido do ETD (Tandem Duplo), com 33,26\%. Além destes, o ESRD (eixo simples de roda dupla), o ETT (Tandem Triplo) e o EDD (eixo duplo direcional) apresentaram um percentual de 17,57\%, 10,16\% e 0,34\%, respectivamente.

Foi considerado que a distribuição de passagens de eixo se manteve constante durante o período avaliado, aplicando-se apenas a variação do crescimento total, sem considerar eventuais diferenças no crescimento de cada eixo. Os dados de volume de tráfego registrados por um radar instalado no $\mathrm{km} 106$, próximo do TMA, indicaram que 78\% dos veículos de carga trafegam pela faixa de rolamento direita, que foi a faixa onde foram feitos os ensaios. Assim, apenas os veículos de carga que trafegavam nesta faixa foram usados no cálculo de dano por fadiga.

Com os dados do radar instalados em 2014, foi possível acompanhar a evolução do tráfego no TMA. Como não haviam registros de 2013, foi considerada uma evolução com comportamento linear entre 2012 e 2014.

Os registros da evolução do tráfego indicaram que entre 2012 e 2014, o volume médio diário teve um acréscimo geral de $20 \%$ para tráfego misto, enquanto que entre os veículos de carga, o crescimento foi cerca de $73 \%$ nos dois primeiros anos de operação da via.

Além da contagem feita em 2012, foi feita também uma pesagem dos veículos de carga que trafegavam na rodovia. Os dados brutos da pesagem foram distribuídos em uma curva normal relacionando os pesos brutos dos eixos (classes) aferidos nas pesagens e a frequência absoluta de cada evento. Foi realizada uma estratificação do perfil representativo de carga em quatro classes de frequências iguais, divididas por seus quartis e representadas pelos valores médios de carga de cada classe da distribuição. Assim, para cada parcela de $25 \%$ do número de passagens de cada eixo, foi atribuído um valor de carga correspondente ao valor médio da classe Tabela 1.

Foi calculado o número $\mathrm{N}$ absoluto de passagens mensal inicial de cada eixo a partir dos dados da contagem feita em 2012, considerando que apenas 78\% dos veículos de carga transitavam na faixa da direita. 
Tabela 1: Número de passagens mensal inicial e valores médios de carga por classe de eixo

\begin{tabular}{|c|c|c|c|c|c|c|c|}
\hline \multirow{2}{*}{ Tipo de Eixo } & \multirow{2}{*}{$\begin{array}{c}N_{D} \\
\text { (Diário) }\end{array}$} & \multirow{2}{*}{$\begin{array}{c}N_{m} \\
\text { (Mensal) }\end{array}$} & \multirow{2}{*}{$\begin{array}{c}N_{m f d} \\
\text { (Mensal na faixa direita) }\end{array}$} & \multicolumn{4}{|c|}{ Médias da carga das classes (kg) } \\
\hline & & & & 10 & 20 & 3은 & 40 \\
\hline 1ESRS & 2417 & 73529 & 57353 & 3367 & 4593 & 5113 & 6788 \\
\hline EDD & 21 & 638 & 498 & 9980 & 11730 & 12580 & 16090 \\
\hline ESRD & 1362 & 41439 & 32323 & 3933 & 6237 & 7699 & 11741 \\
\hline ETD & 1811 & 55084 & 42966 & 7610 & 12956 & 15569 & 20528 \\
\hline ETT & 636 & 19357 & 15099 & 11448 & 19766 & 23114 & 29355 \\
\hline
\end{tabular}

Ao número real acumulado de passagens de cada eixo, foi aplicada uma taxa de crescimento mensal de $2,41 \%$, que corresponde à taxa mensal de crescimento do tráfego de carga nos primeiros 24 meses de operação da rodovia. Foi utilizado um incremento em períodos de 3 meses para cálculo do número de passagens real de cada eixo no período de análise com fins de utilização nos estudos de dano por fadiga.

\section{RESULTADOS E DISCUSSÕES}

\subsection{Resistência à compressão simples}

Na Tabela 2 são mostrados os resultados da resistência à compressão obtidos com o tempo de cura de 7, 14 e 28 dias. Os mesmos atenderam os requisitos da NBR 11803/2013, que prevê uma resistência à compressão mínima de 3,5 MPa aos 7 dias. Os valores médios nesta idade foram de 3,54 MPa e ficaram bem abaixo dos valores indicados nos relatórios de execução do TMA, que apontaram o valor de 5,7 MPa em média. Esta diferença pode ser decorrente de diferenças durante os processos de mistura realizada nas duas datas, ou mesmo diferença na calibração dos instrumentos utilizados. Contudo, não foi possível estabelecer a razão principal da discrepância observada nos resultados.

Os resultados demonstram um crescimento nas demais idades, com a resistência à compressão aos vinte e oito dias quase $18 \%$ maior que aos sete dias. Este ganho de resistência é esperado devido ao processo de cura, pois o cimento continua a hidratação de suas partículas.

Tabela 2: Resistência à compressão simples e resistência à tração na flexão da BGTC

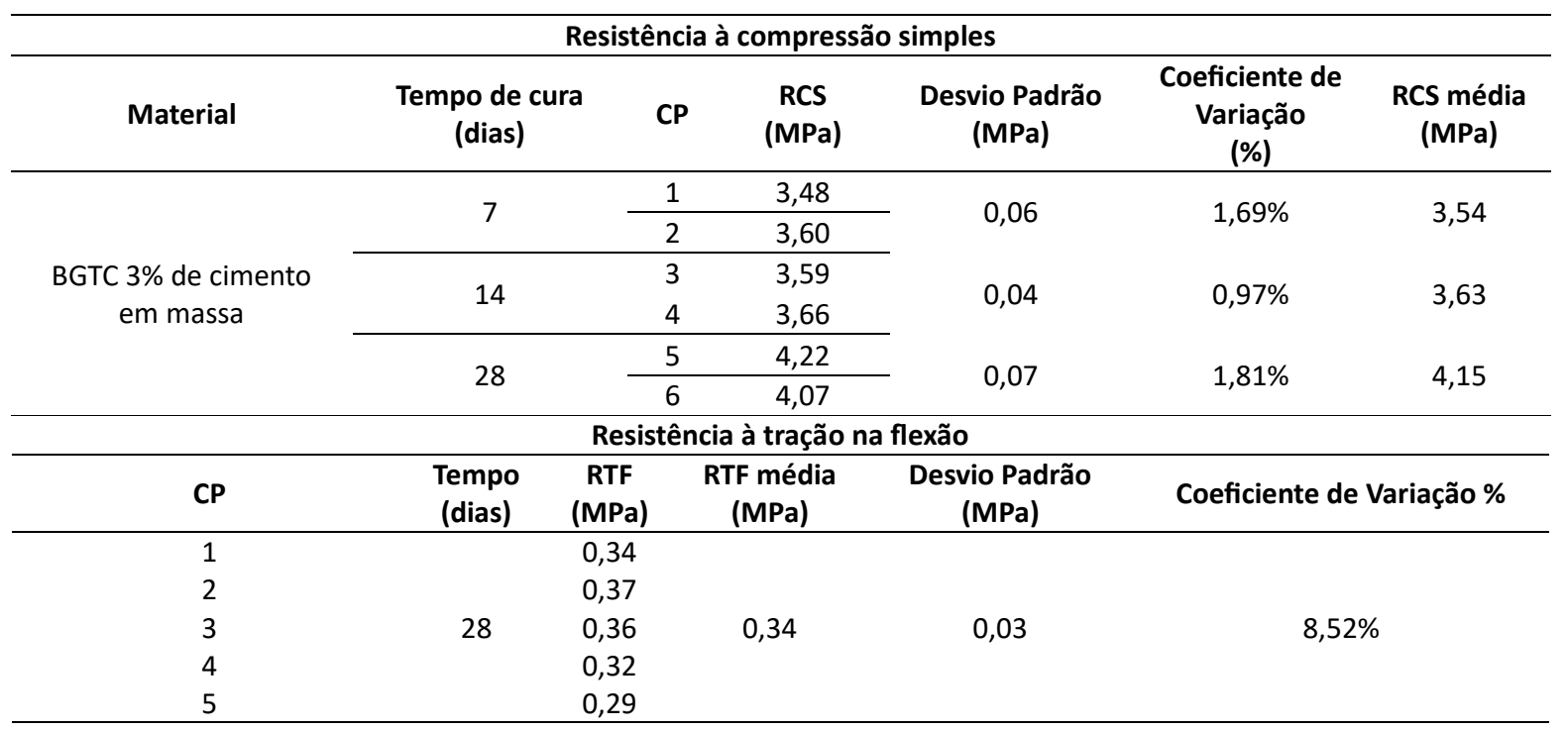

\subsection{Resistência à tração}

Também na Tabela 2 são apresentados os valores de resistência à tração na flexão (RTF). A determinação da resistência à tração da BGTC foi realizada em corpos de prova prismáticos, com grau de compactação de 98\%, em média, da energia do Proctor modificado e com $\pm 0,5 \%$ da umidade ótima. 
Os resultados encontrados de RTF indicaram valores abaixo do esperado segundo as referências consultadas (AUSTROADS, 2008; YEO, 2008). Estes resultados podem ser explicados pelo baixo percentual de cimento na mistura, considerado insuficiente para sua completa estabilização. Além disto, os corpos de prova apresentaram, dentro da tolerância prevista, valores de umidade equivalentes ao ramo úmido da curva de compactação, o que pode trazer uma redução no valor da resistência à tração.

\subsection{Ensaio de fadiga}

A curva de fadiga da BGTC está representada na Figura 5 para a deformação específica de tração inicial correspondente no ensaio de fadiga por tensão controlada. Em todos os casos, o critério de determinação do número $N$, que representa a quantidade de ciclos necessários para a fadiga do material em cada nível de tensão, foi o número de ciclos que o corpo de prova chegou à ruptura clássica. Os ensaios de fadiga do tipo tensão controlada utilizaram níveis de tensão de 75,11\%, 85,88\%, e 90,00\% do valor da resistência à tração na flexão.



Figura 5: Vida de fadiga da BGTC em função da deformação específica de tração.

Pode-se observar na Figura 5 que para uma deformação próxima de 120 microstrains seriam necessários um milhão de ciclos para a mistura do tipo BGTC analisada atingir a vida de fadiga efetiva. Este valor é correspondente ao ensaio de fadiga realizado em um nível de tensão de $70 \%$ da resistência à tração na flexão. Para deformações de tração inferiores, o material teria durabilidade considerada indeterminada e não estaria sujeito à ruptura por fadiga (YEO, 2008).

Um patamar de deformação igual ou superior a 120 microstrains é reconhecidamente aquele no qual ocorrem os danos relacionados à fadiga do material (THEYSE et al., 1996; SAPEM, 2014). Observa-se, portanto, boa convergência do modelo obtido em laboratório, com um comportamento dependente dos níveis de deformação específica de tração, além de ser de ruptura quase-frágil.

A função escolhida como modelo para representar a tendência de vida de fadiga da BGTC obtida em laboratório foi a semilogarítmica, devido à mesma linearizar a relação entre a variável dependente, 0 " $N$ " de fadiga, e a variável independente, que neste caso foi a deformação específica de tração inicial no corpo de prova. À medida que o valor da variável independente cresce o valor do número de ciclos que leva o material à ruptura por fadiga diminui. 


\subsection{Avaliações no Trecho Monitorado}

\subsubsection{Retroanálises e evolução da rigidez da BGTC}

Nesta etapa foi feita a retroanálise das bacias deflectométricas obtidas nos levantamentos de campo com Viga Benkelman Eletrônica e FWD. Neste processo foi possível determinar os módulos de resiliência teóricos de cada camada do pavimento estudado no TMA. Nas análises foram utilizados dados de levantamentos feitos de 2012 a 2016, o que permitiu ver o processo de degradação da camada de BGTC pela diminuição dos valores dos módulos ao longo do tempo (DE ANDRADE et al., 2015).

Os levantamentos feitos especificamente no período desta pesquisa foram realizados nos anos de 2015 e 2016. Os dados entre 2012 e 2014 foram obtidos da pesquisa de Mendonça (2014), que, logo na abertura ao tráfego, extraiu testemunhos das camadas do pavimento e determinou o módulo de resiliência dos materiais em laboratório. No caso da BGTC, como a extração de amostras acarretava em danos aos corpos de prova, optou-se por utilizar o valor do módulo de elasticidade obtido em laboratório durante esta pesquisa. Estes valores de módulo foram utilizados como os iniciais das camadas. Já a evolução dos valores do módulo elástico das camadas foi obtida a partir da retroanálises de bacias deflectométricas, utilizando o programa AEMC. Os valores dos módulos foram distribuídos ao longo do período de análise para verificar a evolução destes valores. Os valores apresentados na Figura 1b são referentes à média dos valores obtidos para cada estaca do trecho monitorado, e representam graficamente a variação dos módulos de resiliência com o tempo.

Percebe-se que os módulos das camadas sofrem uma maior redução entre 2012 e 2014, o que corresponde ao período entre a abertura do tráfego e o pico do crescimento do volume de tráfego. Nos levantamentos seguintes os módulos apresentaram valores mais estáveis, sem grandes variações, com exceção do Binder que ainda apresentou uma perda significativa em sua rigidez devido ao contato direto com a BGTC.

No que se refere à sub-base e ao subleito do pavimento, ambos apresentaram queda expressiva do módulo ao longo dos anos. Este comportamento pode ser explicado pelo tipo de material destas camadas, que nos dois casos, são solos areno-argilosos de comportamento laterítico. A perda de rigidez da base em BGTC e das camadas de concreto asfáltico ao longo do tempo faz com que sejam transferidos para as camadas inferiores níveis de tensões verticais crescentes ao longo do tempo (PIRATHEEPAN, J. e GNANENDRAN, C. T., 2012). Como os módulos de resiliência destes materiais são dependentes da magnitude da tensão desvio, em níveis crescentes com o tempo, estas camadas apresentaram uma queda consistente de rigidez.

A rigidez da base em BGTC teve uma queda expressiva entre 2012 e 2013, chegando em 2014 a valores de módulo de resiliência que indicam o fim da vida de fadiga efetiva ou ruptura da camada por fadiga. Já no ano de 2015, os valores de módulo de resiliência obtidos indicavam uma camada com comportamento equivalente ao de material granular (500 MPa), segundo o método de projeto mecanístico-empírico da África do Sul (SAPEM, 2014). Essa chamada ruptura por fadiga é na verdade uma perda da continuidade da camada, causada por trincas que perpassam sua espessura. Nesta condição a BGTC não funciona mais como uma placa contínua, mas sim em blocos de tamanhos diversos, o que passa a ser um conjunto de menor rigidez, influenciando bastante nos procedimentos de retroanálises de bacias deflectométricas. Não necessariamente significa que este mesmo material, em escala equivalente a corpo de prova, apresentaria tal perda de rigidez.

\subsubsection{Análises de tensões e deformações na BGTC}

Os módulos das camadas foram identificados na Figura 1b para cada 3 meses, a partir da abertura ao tráfego e dentro do período de análise de 21 meses. Os valores das cargas dos eixos, suas frequências e seu crescimento foram obtidos a partir dos estudos de pesagem e contagem volumétrica realizados em 2012. Os valores das cargas, com seus eventuais excessos, foram tratados estatisticamente e agrupados em uma distribuição normal (Curva de Gauss) para verificação do percentual de veículos com excesso de carga que representariam o universo de veículos a partir da amostragem feita na pesagem. 
Tabela 3: Valores de deformação específica e tensão de tração para ciclos de 3 meses

\begin{tabular}{|c|c|c|c|c|c|c|c|c|c|c|c|c|c|c|c|c|c|}
\hline \multirow{3}{*}{$\begin{array}{l}\frac{\pi}{0} \\
\sum \\
\frac{0}{3} \\
\frac{0}{0} \\
\frac{0}{2}\end{array}$} & \multirow[b]{3}{*}{$\frac{\mathscr{y}}{\tilde{y}}$} & \multirow[b]{3}{*}{  } & \multicolumn{15}{|c|}{ Tipo de Eixo } \\
\hline & & & \multicolumn{3}{|c|}{ 1ESRS } & \multicolumn{3}{|c|}{ EDD } & \multicolumn{3}{|c|}{ ESRD } & \multicolumn{3}{|c|}{ ETD } & \multicolumn{3}{|c|}{ ETT } \\
\hline & & & 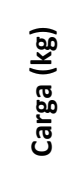 & 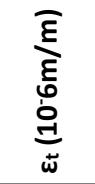 & 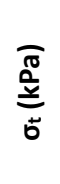 &  & 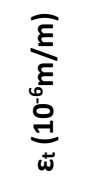 & $\begin{array}{l}\widetilde{\pi} \\
\frac{\sqrt[0]{0}}{\tilde{y}} \\
\dot{0}\end{array}$ & 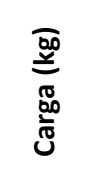 & 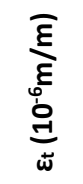 & 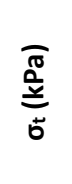 & 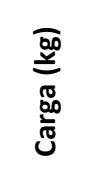 & 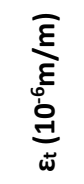 & 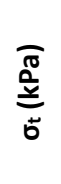 & 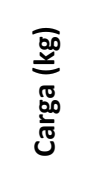 & 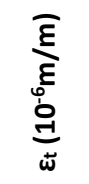 & $\begin{array}{l}\bar{\pi} \\
\frac{0}{y} \\
0 \\
0\end{array}$ \\
\hline \multirow{4}{*}{ 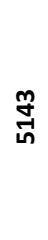 } & \multirow{4}{*}{$\dot{n}$} & 10 & 3367 & 24,2 & 156 & 9980 & 37,4 & 236 & 3933 & 22,2 & 131 & 7621 & 19,5 & 117 & 11448 & 19,2 & 116 \\
\hline & & 20 & 4593 & 33,1 & 214 & 11730 & 43,9 & 277 & 6237 & 35,2 & 208 & 12956 & 32,9 & 197 & 19766 & 32,9 & 198 \\
\hline & & 3음 & 5113 & 36,8 & 238 & 12580 & 47,1 & 297 & 7699 & 43,5 & 256 & 15569 & 39,6 & 238 & 23114 & 38,6 & 232 \\
\hline & & 40 & 6788 & 48,9 & 316 & 16090 & 60,3 & 380 & 11741 & 66,3 & 391 & 20528 & 52,2 & 314 & 29355 & 49,1 & 295 \\
\hline \multirow{4}{*}{  } & \multirow{4}{*}{$\begin{array}{l}0 \\
\dot{I}\end{array}$} & 10 & 3367 & 24,6 & 124 & 9980 & 37,4 & 185 & 3933 & 22,0 & 101 & 7621 & 19,8 & 91 & 11448 & 19,5 & 90 \\
\hline & & 20 & 4593 & 33,5 & 169 & 11730 & 44,0 & 218 & 6237 & 34,9 & 160 & 12956 & 33,7 & 154 & 19766 & 33,6 & 156 \\
\hline & & 3은 & 5113 & 37,3 & 188 & 12580 & 47,2 & 234 & 7699 & 43,1 & 198 & 15569 & 40,5 & 185 & 23114 & 39,3 & 183 \\
\hline & & 4ㅇ & 6788 & 49,6 & 250 & 16090 & 60,4 & 299 & 11741 & 65,7 & 302 & 20528 & 53,4 & 244 & 29355 & 49,9 & 232 \\
\hline \multirow{4}{*}{ 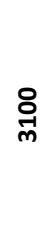 } & \multirow{4}{*}{ 穴 } & 10 & 3367 & 29,4 & 109 & 9980 & 44,7 & 162 & 3933 & 26,4 & 88 & 7621 & 23,5 & 79 & 11448 & 23,4 & 79 \\
\hline & & 20 & 4593 & 40,1 & 148 & 11730 & 53,5 & 191 & 6237 & 41,8 & 140 & 12956 & 40,0 & 135 & 19766 & 40,4 & 136 \\
\hline & & 3응 & 5113 & 45,5 & 165 & 12580 & 56,7 & 205 & 7699 & 51,1 & 171 & 15569 & 48,1 & 162 & 23114 & 47,2 & 159 \\
\hline & & 4o & 6788 & 59,3 & 219 & 16090 & 72,1 & 262 & 11741 & 78,7 & 263 & 20528 & 63,5 & 214 & 29355 & 60,0 & 203 \\
\hline \multirow{4}{*}{ 음 } & \multirow{4}{*}{ خิ } & 10 & 3367 & 36,5 & 88 & 9980 & 55,3 & 132 & 3933 & 32,7 & 72 & 7621 & 29,4 & 65 & 11448 & 28,7 & 63 \\
\hline & & $2^{\circ}$ & 4593 & 49,8 & 121 & 11730 & 65,0 & 155 & 6237 & 51,8 & 114 & 12956 & 49,9 & 110 & 19766 & 50,4 & 111 \\
\hline & & 3응 & 5113 & 55,5 & 134 & 12580 & 69,8 & 166 & 7699 & 63,9 & 140 & 15569 & 60,0 & 132 & 23114 & 58,9 & 130 \\
\hline & & 40 & 6788 & 73,6 & 178 & 16090 & 89,2 & 213 & 11741 & 97,5 & 214 & 20528 & 79,1 & 175 & 29355 & 74,9 & 165 \\
\hline \multirow{4}{*}{ 员 } & \multirow{4}{*}{ 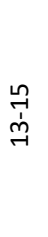 } & 10 & 3367 & 46,8 & 70 & 9980 & 71,1 & 105 & 3933 & 42,3 & 58 & 7621 & 37,8 & 52 & 11448 & 37,5 & 52 \\
\hline & & 20 & 4593 & 63,9 & 96 & 11730 & 83,6 & 124 & 6237 & 67,0 & 92 & 12956 & 64,3 & 89 & 19766 & 64,9 & 89 \\
\hline & & 3응 & 5113 & 71,1 & 107 & 12580 & 89,7 & 132 & 7699 & 82,8 & 114 & 15569 & 77,3 & 106 & 23114 & 75,9 & 104 \\
\hline & & 40 & 6788 & 94,4 & 142 & 16090 & 114,7 & 169 & 11741 & 126,2 & 173 & 20528 & 102,0 & 140 & 29355 & 96,4 & 133 \\
\hline \multirow{4}{*}{ 只 } & \multirow{4}{*}{$\begin{array}{l}\text { 尚 } \\
\stackrel{1}{6}\end{array}$} & 10 & 3367 & 57,5 & 61 & 9980 & 87,7 & 91 & 3933 & 52,6 & 51 & 7621 & 46,8 & 46 & 11448 & 46,5 & 45 \\
\hline & & 20 & 4593 & 78,5 & 83 & 11730 & 103,1 & 107 & 6237 & 83,4 & 81 & 12956 & 79,8 & 78 & 19766 & 80,4 & 79 \\
\hline & & 3응 & 5113 & 87,4 & 93 & 12580 & 110,5 & 115 & 7699 & 103,0 & 100 & 15569 & 95,8 & 94 & 23114 & 93,9 & 92 \\
\hline & & 40 & 6788 & 116,0 & 123 & 16090 & 141,4 & 147 & 11741 & 157,0 & 153 & 20528 & 126,3 & 123 & 29355 & 119,3 & 116 \\
\hline \multirow{4}{*}{ 员 } & \multirow{4}{*}{ 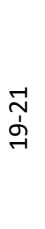 } & 10 & 3367 & 66,7 & 63 & 9980 & 102,1 & 95 & 3933 & 61,7 & 54 & 7621 & 54,5 & 48 & 11448 & 54,0 & 47 \\
\hline & & 2o & 4593 & 91,1 & 86 & 11730 & 120,0 & 112 & 6237 & 97,9 & 86 & 12956 & 93,0 & 82 & 19766 & 93,5 & 82 \\
\hline & & 3응 & 5113 & 101,4 & 96 & 12580 & 128,8 & 120 & 7699 & 120,8 & 106 & 15569 & 111,6 & 98 & 23114 & 109,2 & 96 \\
\hline & & 40 & 6788 & 134,6 & 128 & 16090 & 164,7 & 153 & 11741 & 184,2 & 161 & 20528 & 147,1 & 129 & 29355 & 138,7 & 122 \\
\hline
\end{tabular}

Para avaliar as cargas de cada eixo rodoviário, foi realizada uma estratificação do perfil representativo de carga em quatro classes de frequências iguais, divididas por seus quartis e representadas pelos valores médios de carga de cada classe da distribuição. Assim, para cada parcela de $25 \%$ do número de passagens de cada eixo, foi atribuído um valor de carga correspondente ao valor médio da classe. A partir das análises, foram determinadas as máximas tensões de tração $\left(\sigma_{t}\right)$ e deformações específicas de tração 
$\left(\varepsilon_{t}\right)$ na fibra inferior da camada de BGTC, que são apresentadas na Tabela 3.

0 comportamento do valor médio da tensão de tração e da deformação específica de tração na base da camada de BGTC está ilustrado na Figura 6. É possível observar que à medida que os valores do módulo elástico diminuem ao longo do tempo, os valores da tensão de tração na base também diminuem. O comportamento inverso é observado em relação à evolução da deformação específica de tração na camada de BGTC. Neste caso, a deformação aumenta à medida que o módulo de resiliência diminui.

Até o final do vigésimo primeiro mês, a BGTC passou por um período conhecido por fadiga efetiva. Neste estágio, a camada não resiste aos esforços de tração, uma vez que são dissipados nas trincas que se formam com a ruptura da camada, o que explica a queda no valor da tensão de tração. Já a deformação continua crescendo justamente pela perda desta rigidez. Ao final deste mesmo período, também se observa que a deformação específica de tração média para o eixo simples de rodas duplas supera $120 \mathrm{mi}$ crostrains, deformação esta associada ao limite para ruptura de camadas cimentadas do tipo BGTC (SAPEM, 2014).

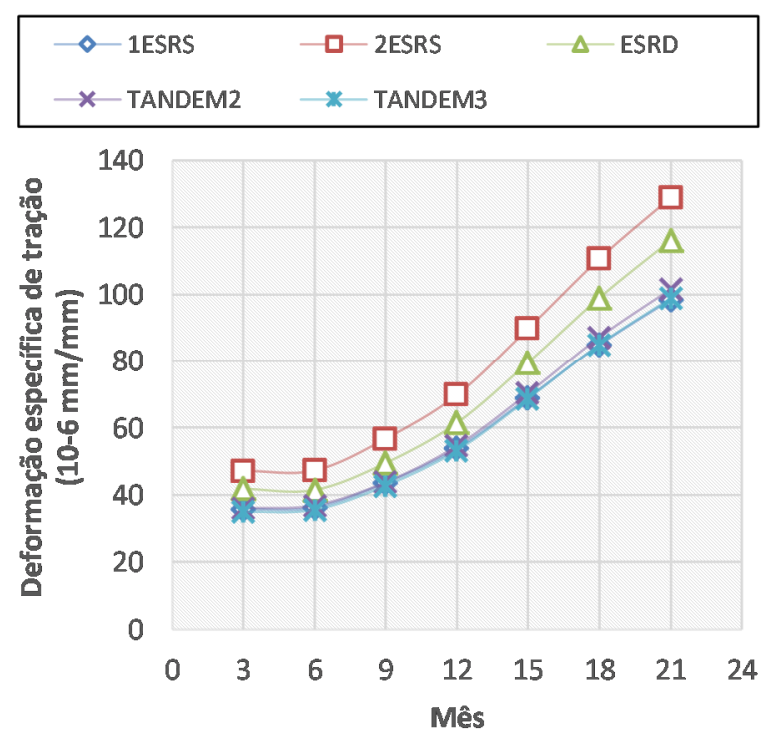

Figura 6: Evolução da (a) tensão de tração e da (b) deformação específica de tração na camada de BGTC ao longo do tempo

\subsection{Modelo de vida de fadiga}

O modelo ajustado a partir do ensaio de tração na flexão com carregamento cíclico utiliza a deformação específica inicial de tração $\left(\varepsilon_{t}\right)$ como variável independente. 0 número de ciclos de carregamento $\left(N_{f}\right)$ que causa a ruptura do corpo de prova é dado por:

Onde:

$$
N_{\text {flab }}=10^{19,0358\left(1-0,00573 . \varepsilon_{t}\right)}
$$

$N_{f l a b}=$ Número de ciclos de carregamento em tensão controlada;

$\varepsilon_{t}=$ Deformação específica inicial de tração do ensaio de fadiga (microstrains).

A forma semi-log de apresentação do modelo foi adotada para simplificar o uso da equação e ser possível uma melhor observação de sua sensibilidade e estimativas. 0 mesmo apresentou diminuições nos valores de $N_{f}$ à medida que crescem os valores iniciais medidos de $\varepsilon_{i}$ nos ensaios de fadiga com tensão controlada.

A complementação da proposta de um modelo de fadiga específico para a BGTC estudada passou por uma etapa de aplicação a um trecho experimental, onde foi possível determinar uma relação entre as análises realizadas em laboratório e em campo, chamado de fator laboratório-campo ou shift factor (SF). 
Foram determinadas, através da teoria do sistema de camadas elásticas, as tensões e deformações iniciais provenientes do perfil de tráfego no TMA (Tabela 3). Os valores das deformações foram aplicados ao modelo de fadiga obtido em laboratório, obtendo com isto, um valor de número de ciclos $N_{\text {lab. }}$ A partir dos dados de tráfego (Tabela 1), incrementados em ciclos de 3 meses, foi determinado o número de passagens de cada eixo $N_{\text {campo }}$. A relação entre o $N_{\text {lab }}$ e o $N_{\text {campo }}$ traduz o dano causado pela passagem de cada eixo, e que somados, estabeleceram o acúmulo de danos à camada de BGTC até que aconteceu o fim da sua "vida de fadiga", ou seja, o dano acumulado foi igual ou maior que $100 \%$. Ao final deste processo, foi estabelecido o valor da relação entre o $N_{l a b}$ e o $N_{\text {campo }}$ acumulado.

0 modelo de fadiga obtido em laboratório estimou, portanto, que o fim da vida de fadiga efetiva ocorreria pouco depois do décimo sexto mês de operação do TMA. Entretanto, em campo, o fim da vida de fadiga efetiva foi definido quando o módulo de elasticidade atingiu o intervalo de $700 \mathrm{MPa}$ a $800 \mathrm{MPa}$ (SAPEM, 2014; AASHTO, 2004), o que ocorreu, segundo os dados de avaliação no trecho monitorado, no vigésimo primeiro mês de operação do trecho. Assim, o número de solicitações de carga ao pavimento em campo (representado pelo somatório da passagem de cada tipo de eixo veicular analisado), que ocasionou a ruptura ao pavimento por fadiga, foi maior que o número de ciclos que o modelo de laboratório previu sob um mesmo nível de deformação.

Como já era esperado, o modelo de laboratório subestimou o número de ciclos necessário para a ruptura do material por fadiga, indicando a fadiga antes da concretização em campo. As curvas que representam este comportamento estão apresentadas na Figura 7. A relação entre o número de ciclos para a fadiga efetiva em campo e em laboratório gera um fator de correção (fator laboratório-campo) apresentado a seguir:

$$
S F=\frac{N_{\text {campo }}}{N_{\text {lab }}}=4,34 \times 10^{5}
$$

Optou-se pela utilização do valor médio das relações entre o número de ciclos em campo e o número de ciclos do modelo de laboratório, o que levou a obtenção de um valor constante para o fator laboratório-campo. Na prática existe uma relação entre campo e laboratório diferente para cada período incremental de 3 meses e que diminui à medida que o dano a camada cresce, ou seja, nos primeiros períodos têm-se camadas mais rígidas e mais ciclos de carregamento, o que gera um fator laboratório-campo alto. Com o avanço do tempo as camadas perdem rigidez e o número de repetições de carga diminui, o que levaria a um fator laboratório-campo menor. Este comportamento seria traduzido por uma equação e não por uma simplificação como foi feita. Embora para uma análise da evolução dos danos haja diferença entre o fator laboratório-campo constante ou não-constante, para a obtenção do momento que a fadiga efetiva é atingida, as duas formas fornecem resultados semelhantes.



Figura 7: Comparação entre modelos de fadiga de laboratório e ajustado para campo. 
O fator laboratório-campo foi incorporado ao modelo, gerando uma nova equação que prevê o desempenho da BGTC, em função da deformação específica de tração, sob as condições de carregamento específicas do trecho monitorado:

Onde:

$$
N_{f}=4,34 \times 10^{5} \cdot\left[10^{19,0358\left(1-0,00573 . \varepsilon_{t}\right)}\right]
$$

$N_{f}=$ Número de ciclos de carregamento até a ruptura da camada de BGTC;

$\mathcal{E}_{t}=$ Deformação específica de tração na camada de BGTC (microstrains).

0 ajuste do modelo com dados reais do trecho monitorado o qualifica com condições de prever com melhor precisão o comportamento da camada de BGTC em campo a partir de ensaios de laboratório. Isto torna possível seu uso para dimensionar um pavimento submetido a condições de tráfego, clima e propriedades mecânicas semelhantes, prevendo seu tempo de vida útil de acordo com a sua integridade estrutural.

\subsection{Modelo de módulo em função do dano acumulado}

A partir do ajuste realizado com os dados de campo, foi possível expressar, em termos de modelo estatístico, uma relação entre o dano acumulado e a rigidez da camada. É apresentado na Figura 8 o comportamento do módulo de resiliência em relação ao dano acumulado, para períodos consecutivos (t) de 3 meses até a ruptura por fadiga, ou seja, até que o dano atinja 100\%. Foram contabilizados os danos acarretados por cada eixo de carga, de acordo com o modelo da equação 5 já ajustado para campo, e relacionados ao módulo de resiliência inicial de cada período.

A melhor linha de tendência ajustada para o gráfico da relação entre dano e módulo de resiliência foi avaliada pelo maior valor de coeficiente de determinação, e permitiu ajustar um modelo para o dano acumulado a partir dos dados desta pesquisa, com nível de confiança estatística de $95 \%$ e com coeficiente de determinação $\mathrm{R}^{2}=0,99$.

\begin{tabular}{cccc} 
Período & Meses & $\begin{array}{c}\text { MR } \\
\text { BGTC } \\
\text { (MPa) }\end{array}$ & $\begin{array}{c}\text { Dano } \\
\text { Acumulado } \\
\text { (\%) }\end{array}$ \\
\hline $\mathbf{1}^{\circ}$ & $0-3$ & 5143 & $\mathbf{0 , 0}$ \\
\hline $\mathbf{2}^{\circ}$ & $4-6$ & 4150 & $\mathbf{0 , 0}$ \\
\hline $\mathbf{3}^{\circ}$ & $7-9$ & 3100 & $\mathbf{0 , 0}$ \\
\hline $\mathbf{4}^{\mathbf{o}}$ & $10-12$ & 2100 & $\mathbf{0 , 0}$ \\
\hline $\mathbf{5}^{\circ}$ & $13-15$ & 1350 & $\mathbf{0 , 0}$ \\
\hline $\mathbf{6}^{\mathbf{0}}$ & $16-18$ & 970 & 0,10 \\
\hline $\mathbf{7}^{\circ}$ & $19-21$ & 850 & 100 \\
\hline
\end{tabular}

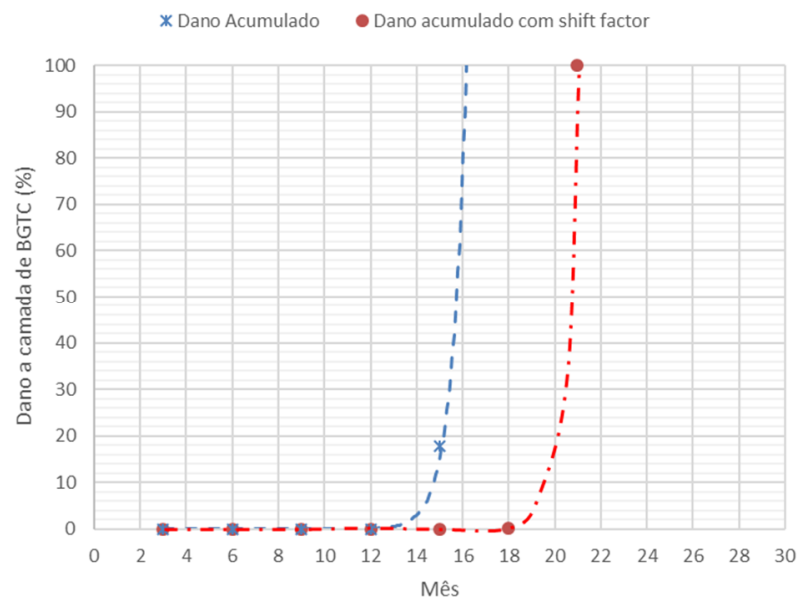

Figura 8: Dano acumulado na camada de BGTC do TMA antes e após ajuste em campo.

O modelo representado pela equação 6 utilizou uma estrutura sigmoidal da relação entre dano acumulado e o módulo de resiliência da camada, baseada no modelo do guia de dimensionamento da AASHTO (2004):

Onde:

$$
E(t)=E(\min )+\frac{[E(\max )-E(\min )]}{\left[1+e^{(4,07259+0,40842 \cdot \log D)}\right]}
$$

$E(t)$ = novo módulo de elasticidade no período t em um nível de dano D (MPa)

$E(\max )=$ módulo de elasticidade para a camada intacta $(\mathrm{MPa})$; 
$E(\min )=$ módulo de elasticidade final da vida de fadiga efetiva (MPa);

$D=$ nível de dano em escala decimal (por exemplo, $\mathrm{D}=0,6$ ).

\section{CONCLUSÕES}

0 modelo de previsão de desempenho à fadiga, ajustado com base de dados de laboratório, apresentou um bom desempenho para explicar o fenômeno de fadiga da mistura de BGTC estudada. Esta conclusão está baseada no fato de, quando aplicado aos dados de deformação obtidos nos levantamentos de campo, este indicar um processo de degradação por fadiga próximo daquele observado em campo, além de ser bastante sensível a deformações específicas de tração na ordem de 120 microstrains, patamar responsável por gerar fadiga em materiais tratados com cimento.

A relação entre o número real de passagens da carga e o número de ciclos de carregamento do modelo de laboratório permitiu estabelecer um fator laboratório-campo. Este fator, quando estabelecido como uma constante, indicou que, para alcançar os mesmos níveis de dano na camada de BGTC em operação ao tráfego, são necessários valores $4,34 \times 10^{5}$ vezes superiores ao número de carregamentos aplicados no ensaio de fadiga.

O ajuste de um modelo que relaciona o comportamento do módulo de resiliência da camada de BGTC com a evolução do nível de dano à camada, a partir da aplicação do princípio da Hipótese de Miner, constitui uma importante ferramenta para dimensionamento do pavimento e para o acompanhamento da degradação estrutural da camada ao longo do tempo, respeitando condições semelhantes àquelas encontradas nesta pesquisa.

Fazer uma previsão da rigidez de uma camada de pavimento ao longo do tempo é uma importante ferramenta para gerenciar a manutenção e recuperação de uma rodovia. A aplicação deste modelo, neste caso, é possível a partir de dados de tráfego, ou seja, estabelece-se a relação entre o " $N$ " real e o " $N$ " estimado pelo modelo de fadiga apresentado neste trabalho, determinando em qual nível está o dano à camada, prevendo assim, em qual período ocorrerá a fadiga efetiva do material.

A partir do estudo de comportamento à fadiga, é possível concluir que o uso da base em BGTC na rodovia onde está localizado o trecho monitorado não foi bem-sucedido. 0 seu processo de degradação acelerado, que ocorreu nos primeiros dois anos de uso, em parte, pode ser atribuído ao crescimento atípico do tráfego nos primeiros anos e do excesso de carga relacionado a este tráfego. Contudo, os níveis de tensão e deformação registrados na camada de BGTC neste período foram determinantes na ruptura precoce da base. Neste sentido, o posicionamento de uma camada cimentada rígida como base, ou seja, em contato direto com um revestimento flexível, foi o que fez com que os esforços na BGTC alcançassem tal magnitude.

\section{AGRADECIMENTOS}

Ao CNPq pelo apoio financeiro a realização desta pesquisa, a partir de projeto contemplado no Edital MCTI/CNPQ/Universal $14 / 2014$.

\section{REFERÊNCIAS}

AASHTO (2014) Guide for Mechanistic-empirical Design of New and Rehabilitated Pavement Structures, NCHRP 1-37A. Washington, DC: Transportation Research Board.

ASTM (2015). Standard Test Method for Flexural Strength of Concrete (Using Simple Beam with Third-Point Loading) ASTM C78/C78M-15a. 4p. DOI: 10.1520/C0078_C0078M-15B.

AS 1012, Australian Standard (2000) Testing Concrete. Standards Australia, Sydney.

AUSTROADS (2004) Pavement Design - A Guide to the Structural Design of Road Pavements. AUSTROADS.

De Andrade, L. R.; A. K. Kuchiishi; I. S. Bessa; K. L. Vasconcelos; L. L. B. Bernucci; I. A. Beja; J. M. Chaves (2015) Comportamento mecânico de camadas de bases granular e tratada com cimento em rodovia de tráfego muito pesado. Anais do XXIX Congresso de Pesquisa e Ensino em Transportes, ANPET, Ouro Preto, p. 148 - 159.

DNER-ME 83 (1998). Agregados - Análise Granulométrica. Departamento Nacional de Estradas de Rodagem - Método de Ensaio, Rio de Janeiro, RJ, Brasil.

DNIT. (2010) ME 133/2010 Pavimentação asfáltica - Delineamento da linha de influência longitudinal da bacia de deformação por intermédio da Viga Benkelman -Método de Ensaio. Rio de Janeiro- RJ, 2010. 
Franco, F. A. (2007) Método de Dimensionamento Mecanístico-empírico de Pavimentos Asfálticos - SISPAV.. Tese (Doutorado) Coordenação dos Programas de Pós-graduação de Engenharia, Universidade Federal do Rio de Janeiro. Universidade Federal do Rio de Janeiro. Rio de Janeiro, RJ.

Gnanendran, C. T. e K. P. Dalim (2016) Fatigue Characterization of Lightly Cementitiously Stabilized Granular Base Materials Using Flexural Testing. Journal of Materials in Civil Engineering, v. 28, n. 9, p. 04016086. DOI: 10.1061/ (ASCE) MT.19435533.0001598

Jitsangiam, Peerapong et al (2016) Fatigue Assessment of Cement-Treated Base for Roads: An Examination of Beam-Fatigue Tests. Journal of Materials in Civil Engineering, v. 28, n. 10, p. 04016095. DOI: 10.1061/ (ASCE) MT.1943-5533.0001601

Mendonça, A. T. de (2014) Avaliações Funcionais e Estruturais Preliminares de Trechos Monitorados na Rodovia BR-101/SE. Dissertação (Mestrado) - Universidade Federal de Sergipe, São Cristóvão.

Nascimento, R. S. (2017) Estudo de Desempenho à Fadiga de Base Cimentada Tipo BGTC na BR-101/SE. Dissertação (Mestrado) - Universidade Federal de Sergipe, São Cristóvão.

SAPEM, South African Pavement Engineering Manual (2014). South African National Roads Agency Ltd.

Park, Sun e Y. Kim (1997) Temperature correction of back calculated moduli and deflections using linear viscoelasticity and time-temperature superposition. Transportation Research Record: Journal of the Transportation Research Board, n. 1570, p. p. 108-117. DOI: $10.3141 / 1570-13$

Piratheepan, J. e C. T. Gnanendran (2012) Back-calculation of resilient modulus of lightly stabilized granular base materials from cyclic load testing facility. Journal of Materials in Civil Engineering, v. 25, n. 8, p. 1068-1076. DOI: 10.1061/ (ASCE) MT.1943-5533.0000653

Theyse, H.; M. De Beer e F. Rust (1996) Overview of South African mechanistic pavement design method. Transportation Research Record: Journal of the Transportation Research Board, n. 1539, p. 6-17. DOI: 10.3141/1539-02

Yeo, R. (2008) The development and evaluation of protocols for the laboratory characterization of cemented materials. 